\title{
Reflexões sobre o ensino de língua materna: a (não) formação do aluno leitor e produtor de textos-enunciado
}

\author{
Josa Coelho da Silva Irigoite \\ Universidade Federal de Santa Catarina
}

\begin{abstract}
Resumo
Este artigo traz um recorte de uma pesquisa de Dissertação cujo tema é a aula de Português, com foco em fatores que comprometem a formação dos alunos como leitores e produtores de textos-enunciado escritos em diferentes gêneros discursivos. O objetivo era identificar razões pelas quais as aulas de Português não acontecem no espaço escolar em estudo, em se tratando do ensino e da aprendizagem da leitura e da produção textual escrita. A tipificação da pesquisa constitui uma pesquisa-ação, com ancoragem etnográfica, cuja geração de dados partiu da inserção em uma escola estadual do município de São José/SC, nas aulas de Português de uma turma de $1^{\circ}$ ano do ensino médio. Tendo a aula de Português concebida como acontecimento (Geraldi, 2010) e como gênero discursivo (Matencio, 2001), conclui-se que essas aulas não aconteceram de fato por não haver engajamento por parte dos alunos.
\end{abstract}

Palavras-Chave: Aula de Português; gêneros do discurso; leitura; produção textual.

\begin{abstract}
This paper provides an outline of dissertation research whose topic is the Portuguese class, focusing on factors that compromise the students' development as readers and producers of written texts-utterance in different genres. The objective was to identify reasons for the Portuguese classes not happening in the school under study, in terms of the teaching and learning of reading and written text production. The type of research was action research, anchored in an ethnographic study, and the data were generated in a state school in the city of São José/SC, in the Portuguese classes of one first-year high school group. With the Portuguese class having been designed as an event (GERALDI, 2010) and as a speech genre (MATENCIO, 2001), it follows that these classes did not happen in fact precisely because there is no engagement on the part of the students.
\end{abstract}

Keywords: Portuguese classes, speech genres, reading, text production

\section{INTRODUÇÃOO}

A importância que a escrita tem e as funções que desempenha atualmente na vida de comunidades distintas é objeto de estudo na Linguística Aplicada - teorizações sobre letramento são exemplos disso - e tem profundas relações com o recorte deste artigo. Em se tratando de ambientações crescentemente mais marcadas pela presença dessa modalidade da 
língua, como os contextos urbanos perpassados pelas diferentes tecnologias, possivelmente nunca os homens que vivem nessas ambientações estiveram tão rodeados por material escrito e possivelmente, ainda, nunca as demandas por dominar essa modalidade em suas diferentes configurações tenham se estabelecido de igual modo.

Paradoxalmente, porém, em determinados contextos, parece não haver leitores e produtores de textos para muitos gêneros discursivos que instituem essa profusão de textosenunciado ${ }^{1}$. Essa é uma discussão que tem se consolidado nas últimas décadas e que geralmente se volta para a escola, instituição historicamente concebida como responsável pela formação do leitor e produtor de textos - em tese, a principal agência de letramento (KLEIMAN, 2001 [1995]) -, processo implicado na formação do cidadão, dadas as relações historicamente construídas entre cidadania e escolarização e erudição (GRAFF, 1994). Uma pergunta frequente entre os professores, como já apontava Kleiman (2001 [1989]) no final dos anos 1980, é: “Por que meu aluno não gosta de ler?”. Talvez as melhores perguntas sejam: O que e para que nossos alunos leem e escrevem em nossas sociedades grafocêntricas contemporâneas? Estamos formando leitores e produtores de textos-enunciado em nossa ação escolar? Mas o que significa formar produtores de textos-enunciado?

Dados de indicadores como o Indicador Nacional de Alfabetismo Funcional (Inaf) e testes internacionais aplicados pelo Programa de Avaliação Internacional de Estudantes (Pisa) sinalizam para um baixo rendimento de brasileiros de diferentes regiões do país nos usos da modalidade escrita. Olhares mais pontuais também tendem a confirmar essa preocupação que emerge dos dados dos indicadores massivos: são os trabalhos de estudiosos que levantaram problemas da aula de Português nas últimas décadas - Geraldi (1997 [1991]), Kleiman (2001[1989]), Britto (1997), Antunes (2003), Batista (1997), Zilberman (1993), apenas para citar alguns deles. Esses estudos nos fazem pensar mais detidamente sobre nosso papel na ressignificação das práticas de leitura e escrita de nossos alunos, sobretudo nos entornos menos privilegiados socioeconomicamente.

Pensando nesses questionamentos, este artigo traz um recorte de uma pesquisa-ação realizada em uma turma de $1^{\circ}$ ano do ensino médio de uma escola estadual do município de São José/SC, que incluiu observação participante de 23 aulas de Português da professora local, com geração de notas de campo, e minha ação protagonista ao longo de 24 aulas, além de entrevistas e pesquisa documental. A inserção na escola nasceu da vontade de construir

\footnotetext{
${ }^{1}$ Usarei essa denominação por adotar a concepção de texto como unidade de interação, tal qual propõe o Círculo de Bakhtin.
} 
inteligibilidades para o que parece ser um problema linguístico socialmente relevante (MOITA LOPES, 2006): potenciais dificuldades para ressignificar práticas de leitura e escrita de alunos inseridos em ambientações com baixos níveis de escolarização e socioeconomicamente desprivilegiadas. As aulas em questão tiveram como foco norteador o gênero crônica, encaminhamento feito pelas Olimpíadas de Português, concurso do qual tal turma iria participar no semestre seguinte.

O presente artigo traz os principais desafios encontrados, com uma breve análise das atividades de leitura e produção textual - isso porque, com base em Geraldi (2010), entendese o texto como o eixo da aula de português - tais quais foram vivenciadas ao longo da pesquisa, tanto nas aulas observadas como nas ministradas. Especificidades das produções textuais dos alunos e de seu desempenho na compreensão leitora, que os distanciam de uma performance globalmente esperada, mereceram especial atenção e contribuíram na construção de uma inteligibilidade sobre a realidade vivenciada: as aulas de Português, como gênero discursivo (MATENCIO, 2001), não têm acontecido naquele espaço social e historicamente situado, por não haver engajamento dos alunos. Os fatos observados que levaram a essa conclusão serão exemplificados a seguir.

\section{O ENSINO E A APRENDIZAGEM DA LEITURA E DA PRODUÇÃO TEXTUAL ESCRITA: EIXOS DAS AULAS QUE NÃO ACONTECEM}

Os dados gerados no percurso da pesquisa-ação sinalizam para substantivos desafios no trabalho com a leitura e a escrita de textos-enunciado em gêneros discursivos na esfera escolar, sobretudo em gêneros secundários, a exemplo da crônica. Nesta seção, serão apontados os principais pontos observados e refletidos na pesquisa, referentes à formação do aluno leitor e produtor de textos-enunciado do gênero crônica, mas que possivelmente podem ser generalizados no trabalho com outros gêneros diversos.

\section{A (não) formação de leitores de crônicas na aula de Português}

As observações das aulas auxiliaram significativamente a tentativa de delinear como os gêneros discursivos parecem estar sendo trabalhados em sala de aula. No tratamento dessa questão, o primeiro ponto levantado nas observações participantes é a prevalência da transposição didática (PETIT-JEAN, 2008 [1998]), que contribui para o apagamento da ação 
crítica e reflexiva do professor, em detrimento da elaboração didática (HALTÉ, 2008 [1998]), que constitui atividade complexa e que implica o protagonismo docente no planejamento e no desenvolvimento da ação didático-pedagógica. A vinheta narrativa que compõe a nota de campo a seguir parece ser substancialmente ilustrativa no que diz respeito a essa questão; o conteúdo da nota focaliza o início do trabalho com o gênero crônica empreendido pela professora participante de pesquisa:

(1) A professora da primeira série do ensino médio precisa trabalhar com crônicas porque a escola está participando das Olimpíadas de Língua Portuguesa. Ela não domina o gênero, não tem conhecimentos de referência sobre crônicas e confessa não ter tempo para estudar e ler de modo a apropriar-se dos saberes implicados hoje em sua ação didática. E nem "concorda muito" com a escolha das Olimpíadas: admite em sala nunca ter trabalhado crônica com uma turma de primeiro ano, só no terceiro. Então, lê em voz alta, no livro das Olimpíadas encaminhado pelo MEC, o que é crônica, enquanto os alunos desatentos parecem não ouvir. $O$ foco do material institucional são os autores de crônicas e a natureza dos temas; a esfera de circulação, as interações que o gênero medeia/institui e o modo como os recursos linguísticos são mobilizados para que tais interações aconteçam parecem estar em flagrante segundo plano no tratamento do material em questão (Diário de campo, aula 1, 22/03/2010).

Ao aceitar a sugestão das Olimpíadas e seguir as oficinas exaustivamente descritas no manual, a professora empreendeu o processo de transposição didática (PETIT-JEAN, 2008 [1998]), não do conhecimento tal qual produzido na universidade, mas desse mesmo conhecimento recondicionado e veiculado em documentos oficiais: ou seja, a professora não transpôs da academia, mas de documentos produzidos a partir dela [da academia]. Além disso, a forma como a professora lida com o fato de ter de ensinar a crônica parece suscitar o que Geraldi (2010) aponta como movimento de redução do conceito de gênero sem gênese. Trata-se de um deslocamento do conceito no âmbito do ensino, processo do qual deriva um objeto definido previamente, seriável, unificado e exigido em avaliação nacional - neste caso, o gênero crônica encaminhado, a priori, para todas as turmas do primeiro ano do ensino médio em nível nacional. Na opinião do autor, esse movimento nada tem de bakhtiniano, uma vez que concebe os gêneros discursivos como uma "mercadoria", um "capital escolar vendável e consumível". Eis o olhar no gênero como artefato, que não implica necessariamente uma apropriação significativa. Uma sinalização do resultado negativo desse processo é o fato de que, dois meses após esse período registrado na vinheta - em aulas de cerca de vinte minutos, encurtadas em razão de mazelas institucionais historicamente instauradas na escola e [em aulas] flagrantemente prejudicadas por evidente descaso da turma - um dos alunos, em entrevista diz: (2) "Não aprendi nada nas aulas de português neste ano; não sei ainda o que é crônica." (Entrevista com um aluno que pouco participava das aulas; 
maio de 2010). Talvez seja possível entender, assim, a razão por que, em se tratando desta pesquisa-ação, nenhuma aula dentre as observadas obteve um resultado "satisfatório", esperado pela professora, mesmo advindo da transposição de modelizações institucionalizadas e, portanto, em tese, bem construídas.

Essa primeira vinheta narrativa parece sinalizar para uma "imposição" de construtos teóricos da universidade ao professor em sala de aula, que muitas vezes não faz "sentido" para os envolvidos. A maioria dos alunos, por exemplo, participa das atividades propostas exclusivamente com foco na nota: qualquer proposta apresentada recebia questionamentos por parte dos alunos, tais como "É para entregar?", "Vale nota?". Essa falta de "sentido" nas atividades pedagógicas pode ser exemplificada no trecho a seguir, sobre uma aula na qual a professora apresentou um filme sobre o período de colonização das Américas, intitulado $A$ missão. $\mathrm{O}$ filme tomou três aulas e foi uma indicação do livro didático utilizado na turma. Em todas as aulas em que se passou o filme, percebeu-se uma expressiva falta de interesse por parte da maioria dos alunos, que provavelmente assistiam apenas por esperarem um tipo de "avaliação" posteriormente. Além disso, o trabalho com o gênero materializado no filme parece não ter feito sentido, tanto para os alunos como para a própria professora, que atendeu à sugestão do livro didático:

(3) A professora trouxe a televisão para a sala de aula, para que a turma continuasse assistindo ao filme "A missão", iniciado na aula anterior. O processo de carregar a televisão até à sala, ligar o aparelho e encontrar o ponto em que pararam atrasou em mais de 15 minutos o início da aula. No decorrer do filme, percebi que, de 26 alunos presentes na sala de aula, apenas 9 , aproximadamente, pareciam realmente assistir com atenção. $O$ restante ficava entretido com outras atividades não convergentes com a aula em questão: faziam atividades de outras disciplinas no caderno, conversavam baixinho ou trocavam bilhetes, ouviam música no MP3, $e$ até dormiam ou simplesmente fixavam o olhar em outro ponto da sala que não era a televisão. À medida que o tempo foi passando, mais alunos foram dispersando sua atenção. Os alunos mais atentos ao filme fizeram perguntas, em cujas respostas a professora não demonstrara certeza, apresentando modalizações como "eu acho" e "provavelmente". No final da aula, os alunos a questionaram sobre o motivo de eles assistirem ao filme e se haveria prova ou trabalho depois; ao que a professora respondeu: foi indicação do livro. (Diário de campo, aula 13, 27/04/2010).

Outro fato observado nesse recorte narrativo é novamente a ação da professora de “transpor” uma atividade construída aprioristicamente e veiculada no livro didático, resultado de uma possível não apropriação de conhecimento de referência sobre o gênero materializado no filme, nem informações sobre o conteúdo apresentado. Outro indício deriva do fato de que a professora, sempre que começava a trabalhar com um gênero novo, lia a definição de tal gênero no livro didático ou no material do curso de formação, o que aconteceu, por exemplo, 
na aula em que se iniciou a discussão sobre o gênero crônica. Além da professora, os alunos também demonstraram não familiarização com gêneros recorrentes no ensino escolar.

Por fim, vale mencionar que, nas atividades de leitura em voz alta - muito frequentes nas aulas pesquisadas -, percebeu-se um flagrante problema de decodificação por parte de alguns alunos, o que gerava um sentimento de timidez e vergonha por parte deles e motivava risos e zombaria por parte de colegas. Obviamente isso só gerava mais protestos e negações por parte dos alunos para participarem de atividades que exigissem leitura em voz alta. Se considerarmos que o ato de ler demanda, como condição sine qua non, a decodificação (MORAIS, 1996) e que, havendo dificuldades nessa etapa do processamento da leitura, evidentemente as demais etapas que a sucedem não lograrão êxito, surge a seguinte questão: Como levar a cabo o propósito de formar leitores de crônicas se parcela não pouco significativa dos alunos ainda não desenvolveu automatismos básicos no que diz respeito às relações entre grafemas e fonemas (SCLIAR-CABRAL, 2003)? Sobre tal realidade, assim se enuncia a professora participante da pesquisa: (4) Não sei se deu pra perceber que nas leituras das crônicas eles não leem, não olham o texto, eles ficam escutando só. Eles ficam só escutando. Eles não têm leitura nenhuma. (Entrevista com a professora de português; julho de 2010). Para apropriar-se de determinado gênero discursivo, o aluno precisa ao menos decodificar o texto materializado no gênero, ou seja, precisa estar inteiramente alfabetizado. Dados do Inaf (2009) mostram que, no ensino médio, os níveis de alfabetismo pleno ainda não estão consolidados.

\section{A (não) formação de produtores textuais de crônicas na aula de Português}

No período de intervenção da pesquisa-ação, os alunos da turma do $1^{\circ}$ ano produziram três textos: uma crônica - em duas versões, uma inicial produzida sob orientação da professora, e uma final feita para o blog da turma construído durante a pesquisa -; e uma descrição das atividades relacionadas com escrita em um dia comum no cotidiano dos alunos (ficha de letramento $)^{2}$.

\footnotetext{
${ }^{2}$ Serão utilizados nas legendas dos textos os seguintes códigos: T1 (texto 1: $1^{\circ}$ produção da crônica); T2 (texto 2 : $2^{\circ}$ produção da crônica); T3 (texto 3: descrição das atividades relacionadas com escrita). Após identificar o texto, os alunos serão identificados por número de acordo com a ordem em que aparecem na lista de chamada da professora participante da pesquisa.
} 
Na primeira aula de produção textual, os alunos deveriam apenas escolher um assunto para a crônica a partir de manchetes de jornais e anunciar suas escolhas à professora, que anotou os temas selecionados (orientação do manual das Olimpíadas de Português). Eles poderiam pesquisar mais sobre o assunto em casa para, na segunda aula, produzir a crônica em sala. Mediante o comportamento dos alunos nas seis aulas anteriores - muitas faltas, pouca atenção e participação nas atividades -, tanto quanto mediante a natureza restrita do encaminhamento da produção escrita, o resultado obtido nessa primeira produção textual já era esperado, conforme a avaliação da professora: pouquíssimos alunos produziram realmente um texto-enunciado no gênero crônica. Primeiramente, o número de textos entregues foi extremamente baixo - apenas $47 \%$ dos alunos o fizeram -, assim como todas as atividades propostas pelos professores, consequência do alto número de faltas e do baixo nível de engajamento dos alunos nos eixos propostos para o desenvolvimento de cada aula. Um segundo ponto a considerar é o fato de que, em tais escritos, não se percebe nenhuma relação com as manchetes escolhidas, mas sim um conjunto de temas coincidentes com os levantados pela bibliotecária da escola, em entrevista durante a pesquisa, como sendo os prediletos dos alunos - gravidez, futebol, drogas, relacionamento. Além disso, a grande maioria fixou-se em uma forma possível do gênero crônica, de acordo com as leituras feitas anteriormente; ou seja, como foram lidas várias crônicas configuradas sob forma de diálogos diretos, a exemplo do texto Aquilo, de Luís Fernando Veríssimo (1996), 73\% dos alunos construíram seu texto tomando o "modelo" aprendido, conforme o exemplo a seguir (os textos não estão identificados em razão de demandas éticas):

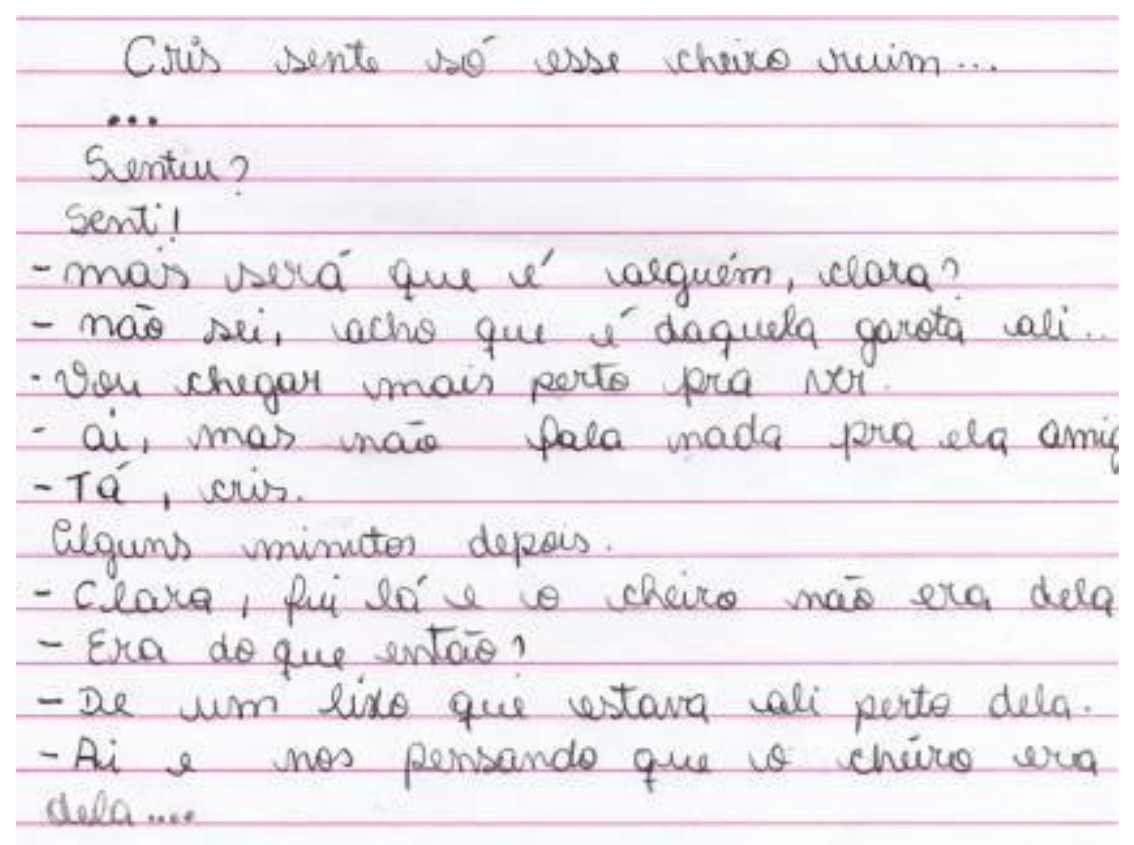


Exemplo 1: T1, aluno n. 15.

Esse texto, tal qual parece evidente, não corresponde à materialização do gênero crônica e, ainda, suscita profundas reflexões sobre a natureza do domínio da modalidade escrita por parte desses alunos, cujo nível de escolarização é o $1^{\circ}$ ano do ensino médio. Produções como essa são ilustrativas da maior parte dos textos discentes produzidos durante a pesquisa. Parece clara a influência das crônicas trabalhadas em aula, nas quais o uso do diálogo direto era recurso recorrente, tanto quanto o humor. Acredita-se que os alunos, assim, haviam entendido que crônica era um texto com diálogo direto, ou seja, uma compreensão muito circunscrita. Além do formato de diálogos diretos, os alunos também parecem ter se fixado no motivo de humor da crônica de Veríssimo: a ambiguidade referencial. Muitos deles parecem ter inferido ser essa uma "regra" do gênero crônica, como no exemplo (2). Visivelmente o efeito não é o mesmo, mas a intenção claramente parece ter sido seguir essa característica da crônica de Veríssimo: escrever um final considerado "surpreendente”, responsável pelo humor do texto.

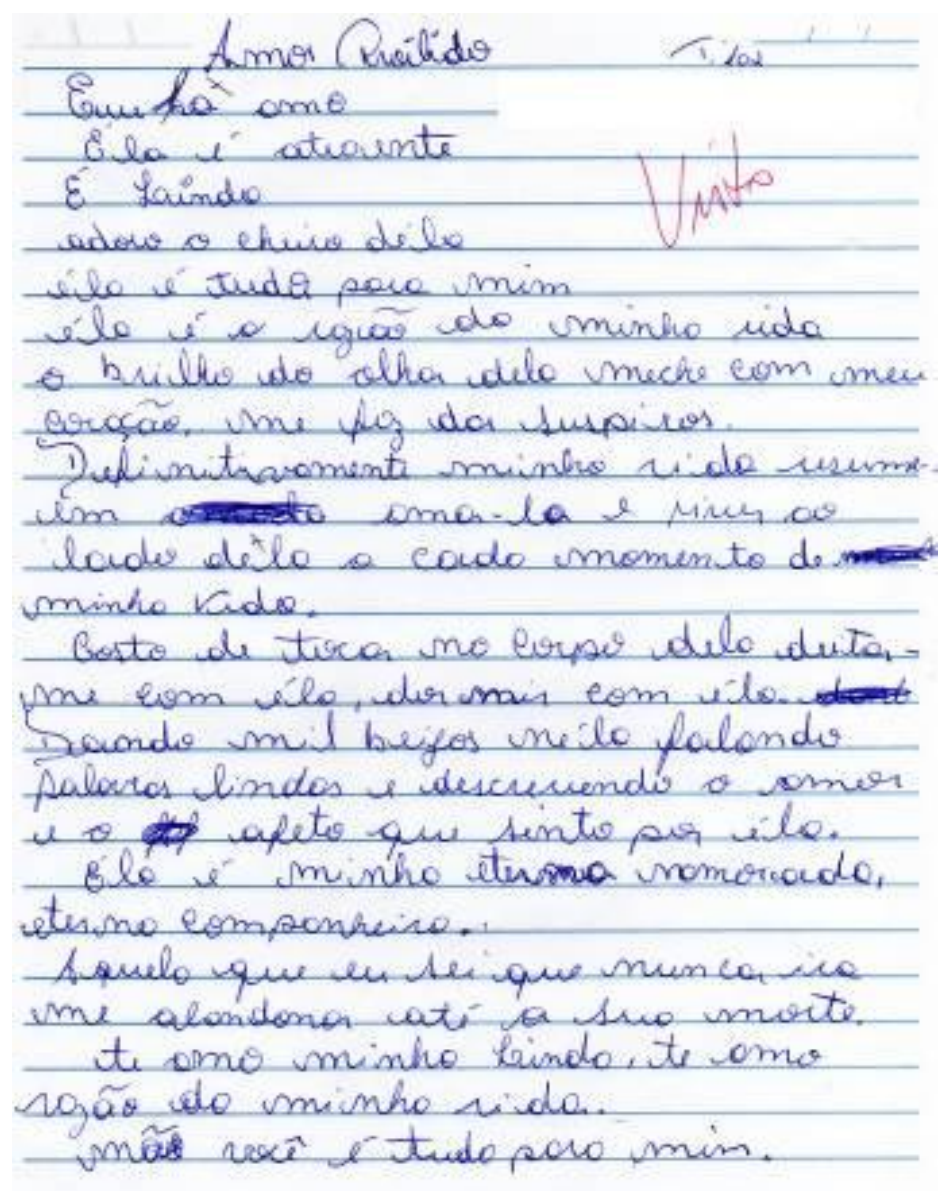

Exemplo 2: T1, aluno n. 23. 
Outro ponto que emerge nesse texto é a precariedade no domínio das estruturas linguísticas correspondentes à norma padrão escrita e a artificialidade de conteúdo, que acabam por deixar os textos difíceis de compreender, incoerentes e não coesos. Tais problemas de não concordância com a norma padrão do português foram foco de correção da professora participante da pesquisa - podemos perceber a correção que ela fez nos trechos em vermelho:

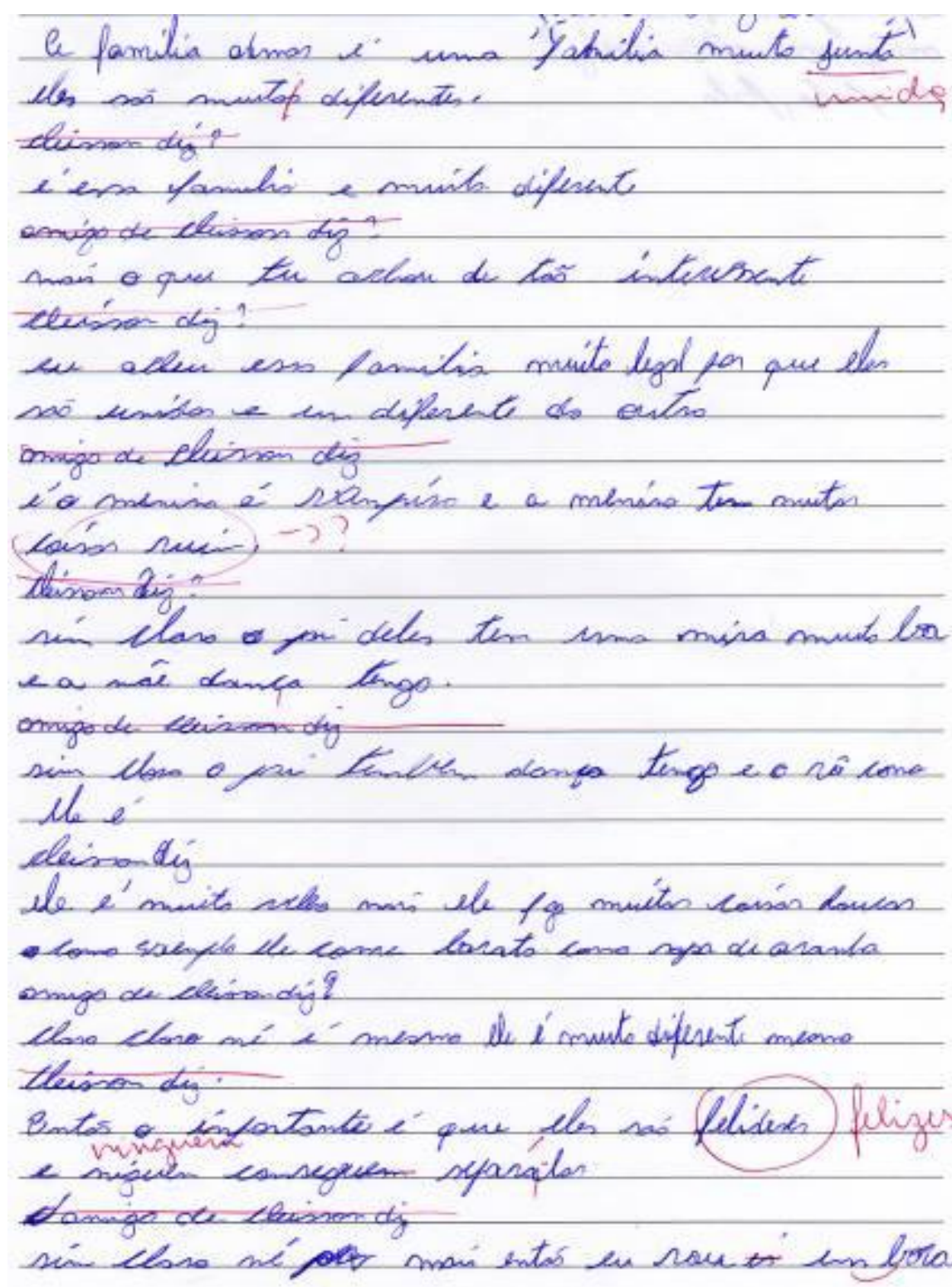

Exemplo 3: T1, aluno n. 35.

Se a escola parece focar, então, na forma dos textos, perguntamo-nos: Será que temos enunciados de fato? Nessas produções textuais escritas, os alunos participantes da pesquisa esperam de fato a reação resposta do interlocutor? E há um interlocutor? Pode-se inferir que 
eles escrevem apenas para a professora. Se cada gênero possui uma concepção típica de destinatário, segundo Bakhtin (2003 [1953/54]), quem seriam os destinatários da crônica dentro e fora da escola? Vê-se nesses textos produzidos uma artificialidade que parece ser típica da esfera escolar (HALTÉ, 2008 [1998]); no entanto, possivelmente a agravante não seja propriamente a artificialidade constitutiva, mas a histórica ausência da dimensão interacional do processo de produção escrita: são anos produzindo textos para o professor ler. Como alterar isso em um contexto como o vivenciado nesta pesquisa parece ser o grande desafio das atividades escolares de produção textual, e Geraldi (1997 [1991]) chamou atenção para esse desafio há duas décadas.

Outro ponto a destacar na produção das crônicas é uma certa "falta de perspectiva" por parte dos alunos, ao demonstrarem não se sentirem "capazes" de produzir um texto em tal gênero. Em uma das últimas aulas de refacção das crônicas, quando a professora começou a cobrar dos alunos que ainda não haviam feito nem a primeira versão, um aluno bem pouco participativo veio me perguntar sobre o que ela estava falando. Ao explicar nossa proposta, ele me perguntou surpreso: (5) Ela quer que eu escreva uma crônica? Eu? (Diário de campo, aula 30, 22/06/2010). E ele não produziu nenhum texto.

A segunda produção textual dos alunos nesse período também apresenta os mesmos problemas: textos curtos, sem muito conteúdo, com sérios problemas de ortografia e até de codificação. Nessa segunda escrita, na décima oitava aula da intervenção, pedi aos alunos que fizessem uma espécie de ficha de letramento, descrevendo todas as atividades relacionadas com a modalidade escrita - leitura e escritura - em um dia comum do cotidiano. Além de demorarem para entender a atividade (levou uma aula inteira de 45 minutos), os alunos apresentaram muita dificuldade em escrever o que lhes foi pedido, afirmavam não "lembrar" de atividades com leitura e escrita. Os pequenos textos produzidos - novamente em número reduzido, apenas $59 \%$ dos alunos o fizeram - apresentam sérias dificuldades de codificação e ortografia e mostram como as práticas de leitura e escrita dos alunos são delimitadas apenas no campo da escola. As poucas atividades listadas que não se relacionam com material escolar são atividades corriqueiras, correspondendo a demandas operacionais de leitura, como no exemplo a seguir: 


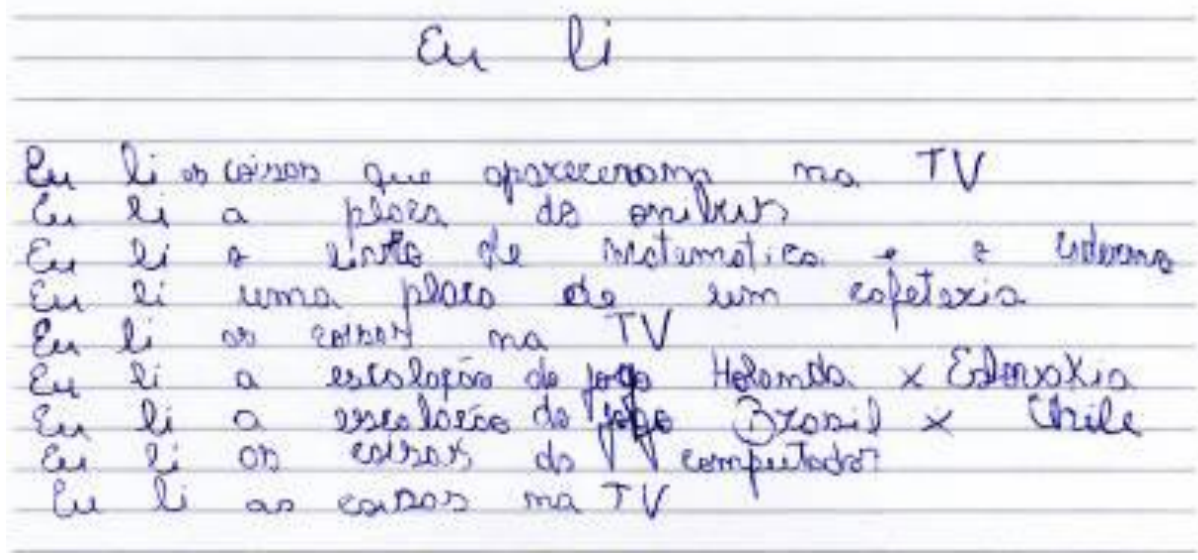

Exemplo 4: T3, aluno n. 17.

Os problemas formais de escrita, como ortografia, concordância e até de codificação (como a junção de certas preposições com substantivo - "demanhã", "detarde") também preocupam por ocorrerem em uma turma de $1^{\mathrm{o}}$ ano de ensino médio e traduzirem conhecimentos sobre segmentação da modalidade escrita (SCLIAR-CABRAL, 2003) que deveriam ter sido internalizados por ocasião dos primeiros anos do processo de escolarização:

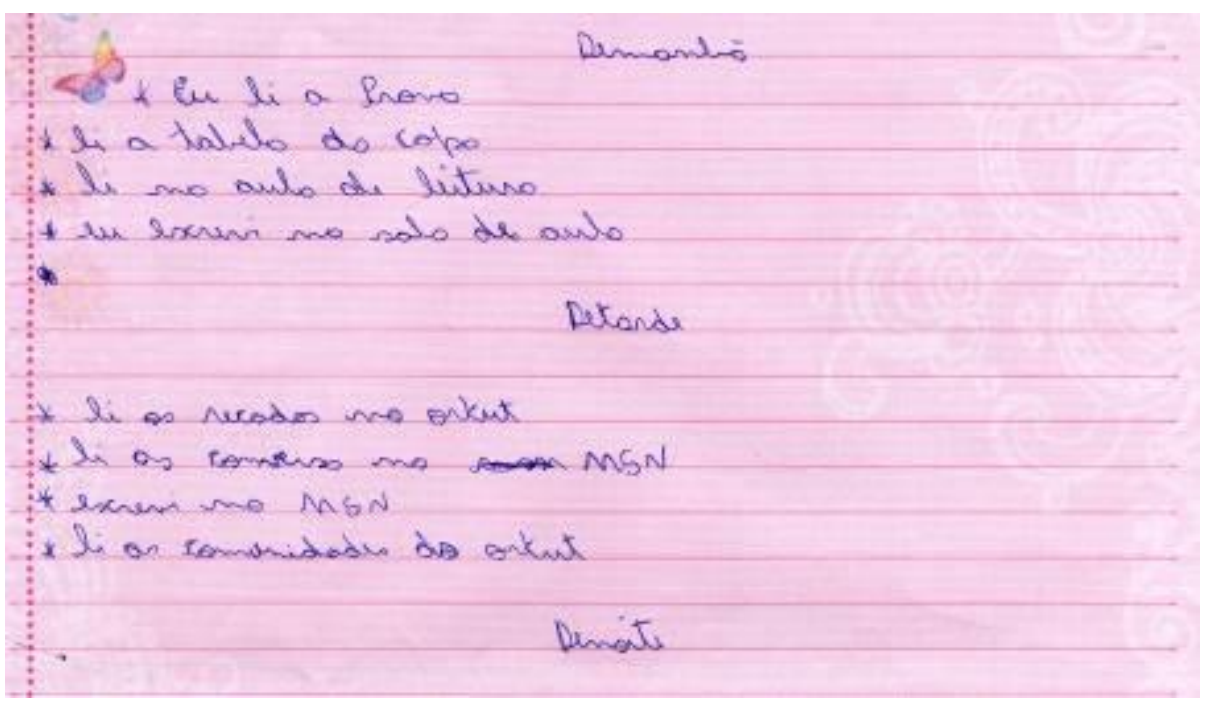

Exemplo 5: T3, aluno n. 15. 


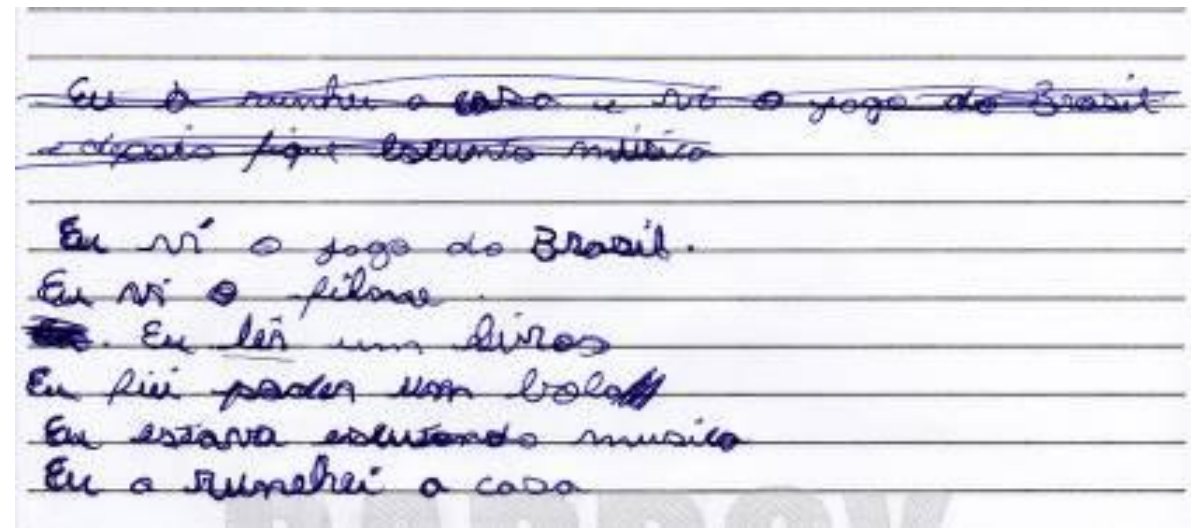

Exemplo 6: T3, aluno n. 7.

O exemplo (6) mostra um fato curioso que aconteceu no transcurso da atividade e que mostra claramente como os alunos não desenvolveram hábitos de leituras diversificadas em seu cotidiano. Percebe-se que na terceira sentença - eu ler um livros - parece que o aluno não sabe conjugar, no pretérito perfeito do indicativo, o verbo "ler" na primeira pessoa do singular (“eu li"). Outro aluno chegou a perguntar oralmente na aula como fazer essa conjugação; ou seja, ele não conseguia/não lembrava como enunciar oralmente "eu li", provavelmente porque a ação correspondente a essa enunciação não fosse prática recorrente de seu cotidiano.

Esses foram apenas alguns desafios levantados, entre outros observados no decorrer da pesquisa, que mostram o quanto tais processos - leitura e produção textual - estão interligados no funcionamento da aula: as produções textuais dos alunos foram, assim, um reflexo do "tipo" de leitura que eles empreendem por meio do qual materializam o conhecimento construído sobre o gênero trabalhado. Em outras palavras: eles entenderam o gênero crônica como um diálogo simples com um final "engraçado", e essa perspectiva visibilizou-se nas produções textuais escritas. Se eles apresentam problemas de decodificação, eliciados na leitura em voz alta, também apresentam problemas de codificação na escrita, o que se estende a conhecimentos básicos como a segmentação do contínuo da fala. Eis possíveis representações de níveis de alfabetismo básico - e não pleno - que se visibilizam nas estatísticas do Inaf (2009) no ensino médio.

\section{Outras pedras encontradas no caminho: obstáculos para a/na aula de Português}

Outros problemas no decorrer da pesquisa também se interpuseram como obstáculos para a almejada formação de leitores e produtores de textos no gênero crônica; agora de 
ordem institucional - problemas de organização da própria escola - e de ordem antropológica - o visível não engajamento dos alunos nas atividades propostas. Parte da pesquisa documental empreendida, o Projeto Político Pedagógico - PPP - da escola em questão, por exemplo, mereceu atenção pelos seguintes desafios: expressivo espaço de tempo decorrido entre uma atualização e outra (dez anos), cujas mudanças foram apenas de caráter instrumental; pouca participação dos professores e da comunidade na atualização do PPP; falta de uma descrição efetiva da comunidade; pouca explicação sobre as vertentes teóricas, sem posicionamento claro em relação a elas; não cumprimento dos objetivos na prática.

Um segundo desafio institucional que emergiu nas observações das aulas da professora participante de pesquisa é a falta de material didático e de estrutura propícia ao trabalho dos professores. A própria professora, em conversas informais durante as aulas observadas, apontou as seguintes limitações: poucos livros didáticos; não disponibilidade de material extra, como cola, tesoura e cartolina; fotocópias limitadas (exigência de 48 horas de antecedência); ambiente "desfavorável" na escola para os professores prepararem as aulas (sem sala própria, sem computador); biblioteca e laboratório de informática pouco utilizados. Também na primeira entrevista, ao ser questionada sobre o que a atrapalha nas aulas, os mesmos problemas foram apontados:

(6) A falta de material na escola, a falta de interesse de alguns alunos, a falta de tempo para que eu me prepare melhor para trabalhar com eles (ultimamente não consigo nem ver jornal), etc. Eu gostaria de ter uma sala de leitura, preparada com equipamentos de vídeo e mídia para que os alunos se deslocassem até ela e tivessem variados tipos de "textos" a disposição. Infelizmente a falta de espaço físico não permite isso. (Entrevista com a professora de português; setembro de 2009).

Além da falta de material didático, as constantes faltas dos funcionários da escola e as trocas de horário foram bastante custosas no decorrer da pesquisa e parecem atrapalhar o trabalho dos professores em geral - e esses fatores emergiram na pesquisa por não serem considerados exceções, mas já como parte do cotidiano da escola. O desafio mais grave, porém, parece ser o tempo "útil" em que realmente uma aula acontece, se descontarmos os minutos iniciais e finais perdidos por conta de diversos fatores como abrir a biblioteca, levar os alunos para a sala de vídeo ou de informática, levar e instalar a televisão na sala, ligar aparelhos eletrônicos como DVD e computador, pegar livros na coordenação, distribuir material, ou simplesmente esperar a "bagunça" dos intervalos diminuir para começar a dar aula. No decorrer da pesquisa, concluiu-se que esses atrasos também faziam parte do cotidiano da escola, ou seja, outro fator que compunha a rotina ali instituída. 
Para exemplificar esse fato, calculou-se o tempo realmente utilizado e o tempo despendido com tais obstáculos nas aulas que constituíram a pesquisa. Na tabela 1, assim, foram divididas as aulas observadas - marcadas com a letra (A) - e as ministradas no período de intervenção - marcadas com a letra (B) - na turma em questão. Para cada conjunto dessas aulas, foram somados, em minutos: o tempo de aula previsto - ou seja, 45 a 50 minutos por aula, conforme consta no programa escolar -, o tempo de aula trabalhado e o tempo de aula despendido a partir dos obstáculos institucionais em minutos e em porcentagem.

\begin{tabular}{l|c|c}
\hline & 1- Ano A (min) & $\mathbf{1}^{\text {a }}$ ano B (min) \\
\hline Tempo de aula previsto & 585 & 1040 \\
\hline Tempo de aula trabalhado & 425 & 799 \\
\hline Tempo de aula despendido & $\mathbf{1 6 0}$ & $\mathbf{2 4 1}$ \\
\hline Tempo de aula despendido (\%) & $\mathbf{2 7 \%}$ & $\mathbf{2 3 \%}$ \\
\hline
\end{tabular}

Tabela 1: Tempos calculados das aulas participantes da pesquisa. Fonte: Construção da autora.

Tanto os alunos quanto os professores demonstraram estar habituados a esses atrasos, fazendo-o por meio de comportamentos semelhantes, demorando sempre para entrar na sala. As constantes interferências externas também contribuíram para que a aula de Português não acontecesse naquele espaço, as quais também deixaram de ser exceções para se tornarem hábitos no cotidiano das aulas observadas. Foram presenciadas cenas recorrentes da diretora autorizando entrada de alunos atrasados ou retirando alunos "bagunceiros"; da coordenadora dando recados e distribuindo carteirinhas; de alunos entrando e saindo da sala e obstáculos afins. Além dos alunos perderem tantos minutos de tempo "útil" de uma aula, o enorme número de faltas foi outro indício do comportamento de desinteresse para com a aula e outro obstáculo para uma construção efetiva de conhecimento. Com tantas faltas e mudanças de turmas entre os alunos, a média de frequência da turma participante de pesquisa foi de apenas $65 \%$.

Como um aluno consegue implementar suas práticas de uso da língua - nesse caso, tendo o gênero crônica como megainstrumento (DOLZ; SCHNEUWLY, 2004) -, se falta a tantas aulas, se a média de frequência é tão baixa? Parece que não há metodologia nem conteúdo didático que compense esse alto índice de faltas. Prova disso é que foram trabalhadas práticas de compreensão leitora e de produção textual escrita por meio do gênero crônica durante 26 aulas consecutivas, fora as da professora participante de pesquisa, e ainda 
ouviu-se, ao final do processo, alunos perguntando "o que era crônica". Essa dificuldade no estabelecimento das interações por parte dos alunos sugere falta de conhecimento relacionado aos tópicos trabalhados em sala de aula. Ora, se não há engajamento de fato do aluno, é possível concluir que não há ensino e, por via de consequência, o aluno não aprende. Não parece haver, portanto, apropriação teórica significativa por parte do aluno sobre o que parece ter sido conteúdo de ensino em aulas pregressas.

\section{CRIANDO INTELIGIBILIDADES: AULAS DE PORTUGUÊS QUE NÃO ACONTECEM}

Diante da realidade descrita, a vivência na escola em que se realizou a pesquisa permitiu a construção, em alguma medida, de inteligibilidades para os problemas encontrados. Se o ensino e a aprendizagem da leitura e da escrita no Brasil parecem constituir um problema linguístico socialmente relevante (MOITA LOPES, 2006), dada a discussão empreendida até aqui, o entendimento dessa problemática pode estar na aula de Língua Portuguesa concebida como gênero do discurso (MATENCIO, 2001). No caso das aulas observadas e ministradas no período da pesquisa, concluiu-se que elas não aconteceram de fato, exatamente por não haver engajamento por parte dos alunos, o que, em boa medida, explica seus baixos índices de assiduidade.

Matencio (2001) analisa a aula de língua materna como um gênero discursivo que caracteriza o discurso didático. Estudando as interações presentes em uma aula de Português, a autora aponta o predomínio de estrutura triádica de pergunta / resposta / avaliação: ou seja, o professor pergunta, o aluno responde, e o professor avalia essa resposta, geralmente corrigindo-a ou reafirmando sua veracidade. A autora também defende que considerar as especificidades da aula de língua materna requer a articulação de diferentes zonas de produção discursiva engendradas na interação didática, conforme demonstra no diagrama a seguir (MATENCIO, 2001, p. 202):

discurso
científico $\begin{gathered}\text { discurso } \\ \text { vulgarização }\end{gathered} \longleftrightarrow \begin{gathered}\text { discurso } \\ \text { didático }\end{gathered} \longleftrightarrow \begin{gathered}\text { interação } \\ \text { didática }\end{gathered} \longleftrightarrow$ AULA

Esse diagrama remete ao percurso aludido anteriormente: construção do conhecimento teórico-científico na universidade, vulgarização desse conhecimento em textos institucionais, 
em manuais de ensino, em cursos de formação e afins, seguida pela elaboração ou transposição didática - dependendo de como esse discurso se organiza e se efetiva - e, enfim, a interação didática que constitui a aula como um dos gêneros por meio dos quais o discurso didático se atualiza. Para que os focos discursivos convirjam ou divirjam, é necessário que haja interação entre professor e alunos e entre alunos e alunos, com engajamento efetivo de ambos os lados. Quando esse engajamento não se dá, não se consolida a aula como gênero discursivo. Matencio (2001) explica como se dá a organização da interação, quando ela acontece de fato:

\begin{abstract}
A organização da interação na aula ocorre por movimentos (didático-discursivos) pelas sinalizações produzidas pelos interactantes na formulação de sua fala - , que direcionam sempre o processo interpretativo e, portanto, interativo e interacional. São essas sinalizações que configuram, passo a passo, a organização acadêmica - a referenciação aos objetos discursivos de ensino/aprendizagem - e a organização social - o estabelecimento de lugares e papéis para os interlocutores -, enfim, a coconstrução de sentidos na interação. (MATENCIO, 2001, p. 174, grifos da autora).
\end{abstract}

Desse modo, a organização da interação na aula implica coconstrução de sentidos por parte do professor e dos alunos, que se tornam, assim, autores que refletem sobre suas vivências, escrevem seus textos e estabelecem novas relações com o já produzido, conforme defende Geraldi (2010). O autor, que concebe a aula de Português como um acontecimento, define o processo de aprendizagem também como construção de conhecimento:

\begin{abstract}
As aprendizagens construídas ao longo do processo de escolaridade podem ser diferentes entre a turma $\mathrm{A}, \mathrm{B}$, ou C: isto não importa, o que importa é aprender a aprender, para construir conhecimentos. Ensinar não é mais transmitir e informar, ensinar é ensinar o sujeito aprendente a construir respostas, portanto só se pode partir de perguntas. [...] a atenção ao acontecimento é a atenção ao humano e a sua complexidade. Tomar a aula como acontecimento é eleger o fluxo do movimento como inspiração, rejeitando a permanência do mesmo e a fixidez mórbida no passado. (GERALDI, 2010, p. 100).
\end{abstract}

Parece possível aproximar Geraldi (2010) das concepções de Matencio (2001) no que respeita ao acontecimento aula, pois ambos destacam a necessidade de engajamento como condição sine qua non para que a aula aconteça. Ora, se o engajamento por parte dos alunos não ocorre, não se dá o movimento apontado por Vigotski (2007 [1978]) no qual um processo interpessoal é transformado em um processo intrapessoal - ou seja, as funções no desenvolvimento da criança aparecem primeiro no nível social, entre pessoas (interpsicológica), e depois no interior da criança (intrapsicológica). Sem engajamento mínimo, portanto, não há o desenvolvimento das funções psicológicas superiores nos alunos. 
Foi exatamente o que aconteceu com os alunos participantes da pesquisa em se tratando do gênero crônica: como conceito científico, tal gênero precisava surgir e se constituir por meio de uma imensa tensão de toda a atividade do pensamento do indivíduo, e não assimilada nem decorada (VIGOTSKI, 2001 [1934]) - eis a apropriação intrassubjetiva por meio das relações intersubjetivas. Partindo, assim, do princípio de que processos internos de desenvolvimento despertam-se do contato do indivíduo com certo ambiente cultural, pergunta-se ainda: Será que as aulas de Português têm facultado esse tipo de contato?

\section{CONSIDERAÇÕES FINAIS}

As vinhetas narrativas e as breves descrições da pesquisa mostram que o trabalho empreendido com o gênero crônica na turma selecionada fracassou, se tomarmos como objetivo a formação dos alunos como leitores e produtores de textos-enunciado desse gênero discursivo. Conclui-se, a partir das aulas observadas e da análise dos materiais escritos produzidos pelos alunos, que a grande maioria deles não se apropriou de fato do gênero crônica. A não apropriação de conteúdo escolar é o resultado da inteligibilidade construída: os alunos não aprenderam o gênero crônica porque as aulas em questão não aconteceram como gênero discursivo, tal qual concebe Matencio (2001). Além disso, podemos inferir que, nesse período de observação participante, não vivenciamos, nas aulas de Português, a proposta reflexivo-operacional enunciada por Geraldi (1997 [1991]) em se tratando do ensino e da aprendizagem de língua materna.

A resposta para tal realidade vivenciada parece estar nos estudos do letramento, se for levado em conta o delineamento da configuração da microcultura dos alunos, feita durante a pesquisa a partir de entrevistas orais e de um questionário socioeconômico. Além do contexto familiar, as práticas de letramento desses alunos mostraram uma provável falta de familiarização deles com o gênero trabalhado. Não só com a crônica, mas com gêneros recorrentes no ensino escolar, a exemplo de conto, romance e poema. E não só estranhamento com a leitura em si, mas também com a prática de mapear as esferas da atividade humana em que os gêneros circulam. Nessas ocasiões, inclusive, observou-se que os alunos leem para a escola, em uma leitura-pretexto (GERALDI, 1997 [1991]), que respondia a uma exigência da escola: ler para aprender o que é uma crônica e produzi-la posteriormente. 
Todas essas dificuldades latentes dos alunos parecem emergir exatamente das especificidades de suas práticas de letramento. A ficha de letramento mostrou o quanto esses alunos entram em contato com a escrita mais significativamente apenas no campo da escola. Fora dela, não parece haver vivências de eventos de letramento recorrentes no cotidiano desses alunos, para o que é ilustrativa a dificuldade de um dos alunos em conjugar o verbo "ler" na primeira pessoa do singular. Infere-se, assim, que a microcultura na qual esses alunos estão inseridos não convergiu com as práticas de letramento escolares, por isso as atividades de leitura e escrita propostas com o gênero crônica não fizeram "sentido" para eles. Nesse caso, a aprendizagem não moveu o desenvolvimento porque a abordagem escolar estava muito além das experiências dos alunos com os usos da modalidade escrita, abordagem que impõe "crônica é adequada para alunos do primeiro ano". Eis a objetificação equivocada a que se refere Geraldi (2010). E a ação escolar não conseguiu atuar na ressignificação dessas práticas, hibridizando práticas de letramento locais e práticas de letramento globais, tal qual propõe Street (2003).

É possível, então, coconstruir um caminho para que as aulas de Português aconteçam? Em outras palavras, deve-se perguntar: É possível que alunos de entornos socioeconomicamente desprivilegiados, que vão para a escola "obrigados", que fazem as atividades em sala de aula visando apenas à nota, que não compartilham vivências com a modalidade escrita como capital cultural, que não alimentam perspectiva de futuro diferentes de seus familiares, que não se consideram com voz na sociedade, produzam de fato uma crônica, ou melhor, queiram produzir uma? Este estudo não alcançou uma única resposta redentora para esses impasses, e nem foi o intuito alcançá-la. Parece que o caminho para uma ação escolar mais efetiva, porém, seja um processo de elaboração didática (HALTÉ, 2008 [1998]) sensível às práticas de letramento locais, mas comprometido em ressignificar essas práticas à luz das práticas de letramento globais, tal qual propõe Street (2003).

O importante aqui é resgatar as discussões acerca da aula de Português, os caminhos em voga nas últimas décadas, e mostrar que a realidade, ao que parece, permanece a mesma. Há uma crise sim no ensino e na aprendizagem da língua materna. A grande questão, portanto, é eliciar um quadro angustiante e refletir na busca por tentar compreendê-lo: professora e alunos ocupando um mesmo espaço físico, por um tempo significativo ao longo do ano e com materiais pedagógicos em circulação nesse mesmo espaço, sem, porém, entabular relações interpessoais que tenham mínimas de modificar/ampliar/ressignificar/enriquecer de fato as representações dos envolvidos sobre os 
usos da língua escrita - e seguramente tantos outros enfoques não considerados aqui - em sociedades que requerem tão mais intensamente essa modalidade da língua a cada dia. E, talvez a questão nodal mais efetiva da angústia: tratar-se de alunos de entornos sociais em que a escola é a única agência capaz de suscitar essas novas representações. Que as discussões levantadas aqui não cessem, até chegar o dia em que a escola com a qual sonhamos cumpra seu papel de agência de letramento, tal qual defende Kleiman (2001 [1995]), dê vozes àqueles reduzidos ao silêncio e transforme a escrita de mecanismo para a exclusão no melhor instrumento de resistência e de inclusão (KLEIMAN, 2001), para o que reflexões sobre empoderamento são substanciais.

\section{REFERÊNCIAS}

ANTUNES, Irandé. (2003). Aula de Português: encontro e interação. São Paulo: Parábola Editorial - (Série Aula; 1$)$.

BAKHTIN, Mikhail. (2003 [1953/54]). Os gêneros do discurso. In: criação verbal. Trad. Paulo Bezerra. 4. ed. São Paulo: Martins Fontes, p. 261-306.

Estética da

BATISTA, Antônio Augusto Gomes. (1997). Aula de Português: discurso e saberes escolares. São Paulo: Martins Fontes - (Texto e Linguagem).

. (2000). Instituto Nacional de Estudos e Pesquisas Educacionais Anísio Teixeira INEP. PISA 2000 - Relatório Nacional. Brasília, Dezembro de 2001. Disponível em <http://www.inep.gov.br/internacional/ pisa>. Acesso em 19 nov. 2008.

BRITTO, Luiz Percival Leme. (1997). A sombra do caos: ensino de língua x tradição gramatical. Campinas, SP: ALB: Mercado de Letras, (Coleção Leituras no Brasil).

DOLZ, Joaquim; SCHNEUWLY, Bernard. (2004). Gêneros e progressão em expressão oral e escrita - elementos para reflexões sobre uma experiência suíça (francófona). In:

Gêneros orais e escritos na escola. Trad. e org. Roxane Rojo e Glaís Sales Cordeiro. Campinas, SP: Mercado de Letras, p. 95-128. - (Coleção As faces da Lingüística Aplicada).

FISCHER, Steven. (2006). História da leitura. São Paulo: UNESP.

GERALDI, João Wanderley. (2010). A aula como acontecimento. São Carlos: Pedro \& João Editores.

. (1997 [1991]). Portos de passagem. 4 ed. São Paulo: Martins Fontes.

GRAFF, Harvey J. (1994). Os labirintos da alfabetização: reflexão sobre o passado e o presente da alfabetização. Porto Alegre: Artes Médicas. 
HALTÉ, Jean-François. (2008 [1998]). O espaço didático e a transposição. In: Fórum Linguístico, Florianópolis, p. 117-139, jul./dez.

INAF BRASIL 2009. Disponível em <http://www.ipm.org.br>. Acesso em 14 set. 2010.

KLEIMAN, Angela B. (Org.). (2001 [1995]). Modelos de letramento e as práticas de alfabetização na escola. In: . Os significados do letramento: uma nova perspectiva sobre a prática da escrita. Campinas, SP: Mercado dos Letras, p.15-64.

. (2001 [1989]). Oficina de leitura. 8. ed. Campinas/SP: Pontes.

(2001). Os usos sociais da escrita e a educação inclusiva no Brasil. II Seminário Internacional Sociedade Inclusiva - Palestras, p. 84-101.

MATENCIO, Maria de Lourdes Meirelles. (2001). Estudo da língua falada e aula de língua materna: uma abordagem processual da interação professor/alunos. Campinas, SP: Mercado das Letras. - (Coleção Letramento, Educação e Sociedade).

MOITA LOPES, Luiz Paulo da. (org.). (2006). Por uma linguística aplicada indisciplinar. São Paulo: Parábola - (Língua[gem]; 19).

MORAIS, José. (1996). A arte de ler. São Paulo: Unesp.

PETIT-JEAN, André. (2008 [1998]). Importância e limites da noção de transposição didática para o ensino do francês. In: Fórum Lingüístico, Florianópolis, p. 83-116, jul./dez.

SCLIAR-CABRAL, Leonor. (2003). Guia prático de alfabetização. São Paulo: Contexto.

STREET, Brian. (2003). Abordagens alternativas ao letramento e desenvolvimento. Teleconferência Brasil sobre o letramento, outubro de 2003.

VERÍSSIMO, Luís Fernando Veríssimo. (1996). Novas comédias da vida privada. Porto Alegre: L\&PM.

VIGOTSKI, L. S. (2007 [1978]). A formação social da mente: o desenvolvimento dos processos psicológicos superiores. Organizadores Michael Cole et. al. Tradução de José Cipolla Neto, Luís Silveira Menna Barreto, Solange Castro Afeche. 7. ed. São Paulo: Martins Fontes.

(2001 [1934]). A construção do pensamento e da linguagem. Tradução de Paulo Bezerra. São Paulo: Martins Fontes.

ZILBERMAN, Regina (org.). (1993). Leitura em crise na escola: as alternativas do professor. 11 ed. Porto Alegre: Mercado Aberto.

\section{A AUTORA}

Josa Coelho da Silva Irigoite possui graduação em Comunicação Social / Jornalismo pela UNISUL (2008) e em Letras Português pela UFSC (2009). Mestre em Linguística (área de concentração: Linguística Aplicada; linha de pesquisa: Ensino e Aprendizagem de Língua 
Materna) pela UFSC (2011). Atualmente é aluna no curso de doutorado do Programa de PósGraduação em Linguística da UFSC (mesma linha de pesquisa) e membro do Núcleo de Estudos em Linguística Aplicada - NELA -, vinculado à mesma instituição. Professora de Ensino e Aprendizagem de Língua Materna da UDESC desde 2012. Pesquisas na área da Linguística: Teoria da Enunciação, Semântica Formal e Linguística Aplicada.

E-mail: josa_coelho@ hotmail.com 